\title{
Energizing effects of combined food and water deprivation upon general activity
}

\author{
JOHN H. WRIGHT, VIRGINIA POLYTECHNIC INSTITUTE, GEORGE A. GESCHEIDER, HAMILTON COLLEGE \\ MARY LEE JOHNSON, WAKE FOREST COLLEGE
}

Following a 16-day period of habituation to the activity wheel under conditions preventing direct reinforcement of the wheel-running response by ingestion the activity of 20 male albino rats was observed during $72 \mathrm{hr}$. of continuous food and water deprivation. Activity increased as a function of deprivation, thus supporting the notion that appetitive drive exerts a directly energizing effect upon behavior.

Although many studies have shown that food deprivation increases general activity few if any provide unambiguous support for one of the most fundamental principles of motivational theory, viz., that drive directly energizes behavior. Virtually all of the studies dealing with this problem have employed a procedure wherein Ss are habituated to the activity device under conditions of ad libitum. feeding prior to the introduction of experimentally imposed deprivation. Thus, the possible establishment of a reinforcement relationship between the activity response and ingestion during the preexperimental habituation period may well explain why Ss became active when later exposed to severe deprivation. Evidence that reinforcement contingencies between activity and ingestion may occur under conditions of ad libitum feeding has been provided by Richter (1927) who observed that rats frequently deprived themselves of food for short periods of time, generally 3 to $4 \mathrm{hr}$. in duration, and often terminated these periods of "voluntary" deprivation with sustained bursts of activity followed immediately by feeding. Thus, the rat's response to experimentally imposed deprivation with increases in activity may occur entirely as a result of a previous history of learning to be active in response to the short periods of "voluntary"' food deprivation characteristic of ad libitum maintenance. Evidence supporting this position has been provided by Finger, Reid, \& Weasner (1960) who reported that 3-hr. fooddeprived rats fed immediately following a 1-hr. session in an activity wheel were subsequently more active under severe food deprivation than 3-hr. food-deprived rats whose feedings following l-hr. sessions in the wheel were delayed $1 \mathrm{hr}$.

In a recent attempt to determine whether food deprivation directly energizes the wheel-running response Finger (1965) eliminated the possibility of prior reinforcement of this response by employing rats having no prior wheel-running experience. He recorded the activity of separate groups of these Ss placed in the wheels for additional periods of deprivation following either 0,24 , or $48 \mathrm{hr}$. of deprivation in the home cage and found activity generally to increase as a function of deprivation. However, in his zeal to prevent the occurrence of reinforcement by ingestion Finger employed procedures which render his results difficult to interpret. Since his rats had not been habituated to the activity wheel all within-S increases in activity under deprivation may well have reflected the gradual development of the locomotor responses essential to wheel running rather than the energizing effects of deprivation. Moreover, all differences in activity among separate groups of unhabituated Ss exposed to different levels of deprivation are equally difficult to interpret since it is well known that the rat's responsiveness to a novel situation is markedly affected by his level of deprivation (e.g., Adlerstein \& Fehrer, 1955; Chapman \& Levy, 1957; Montgomery, 1953; Zimbardo \& Miller. 1958). Consequently, the purpose of the experiment to be reported was to employ an experimental design which would eliminate these factors and thus provide a clear test of whether food deprivation directly energizes wheel running. This was done by habituating Ss to the activity wheel under conditions precluding reinforcement of the wheel-running response by ingestion and later observing the level of activity under deprivation. Method

Subjects. The Ss were 20 experimentally naive male albino rats of the Sprague-Dawley strain, approximately 90 days of age at the beginning of the experiment.

Apparatus and general environmental conditions. The Ss were individually housed throughout the experiment in a small relatively quiet room in which temperature and humidity were controlled by central air-conditioning units. The light-dark cycle of the experimental room was automatically controlled and consisted of two 12-hr. periods. The source of illumination during the 12 light hr. was a 100-watt incandescent lamp suspended overhead. The illumination from two 25-watt red lamps, also suspended overhead and operating continuously throughout the experiment, permitted measurements to be taken during the dark hours. Under these conditions of illumination normal diurnal patterns of both ingestion and activity were observed. Activity wheels of equivalent frictional torque with small side cages were employed. Wheel diameter was 14 in. and wheel tread width was 4.25 in. Number of wheel revolutions was read from Veeder counters mechanically attached to the wheels.

Procedure. The experiment began with a 15-day adjustment period during which Ss were maintained in small home cages on ad libitum food and water rations, and throughout this period daily weight gains indicative of normal growth were exhibited. At the end of this 15-day period the habituation phase of the experiment, the purpose of which was to adapt $S$ to the environment 
of the activity wheel and to establish a stable operant level of wheel running uncontaminated by food or water reinforcement contingencies, was begun. This was accomplished by placing $S$ in the wheel, with neither food nor water available, for $1 \mathrm{hr}$. twice daily, once during the light hours and once during the dark hours, for 16 successive days. The $1-\mathrm{hr}$. wheel sessions were given during the latter hours of the dark cycle and during the early hours of the light cycle. Following each $1-\mathrm{hr}$. exposure to the wheel $\mathrm{S}$ was confined $1 / 2 \mathrm{hr}$. in the side cage before being returned to the home cage and food. A delay of $1 / 2 \mathrm{hr}$. was successful in preventing the establishment of a reinforcement relationship between wheel running and subsequent ingestion in the home cage as evidenced by the finding of a remarkably constant level of activity throughout the entire 16-day habituation period.

At the end of this period all Ss were placed in the wheels and deprived of food and water for the next $72 \mathrm{hr}$. Following 10 days of recovery in the home cage under ad libitum food and water rations Ss were returned to the wheels for a second $72 \mathrm{hr}$. of continuous food and water deprivation.

\section{Results and Discussion}

The results of the present experiment show that in the absence of a history of reinforcement of the wheelrunning response by ingestion there is a direct relationship between the amount of wheel running and level of deprivation. Presented in Table 1 are the means and medians for the activity which occurred during successive 24-hr. periods within each of the two exposures to 72-hr. food and water deprivation. Analysis of variance revealed the effects of deprivation upon mean activity to be highly significant $(F=73.93$, df $=2 / 90, p<.001)$. Furthermore, the highly significant increases in activity with increasing deprivation were present during both exposures to $72-\mathrm{hr}$. deprivation, although there was
Table 1. Wheel Revolutions as a Function of Deprivation

\begin{tabular}{llcrc} 
& & \multicolumn{3}{c}{ Days of Deprivation } \\
& & Day 1 & Day 2 & Day 3 \\
\hline \multirow{2}{*}{ Deprivation 1 } & Mean & 722 & 1,110 & 1,886 \\
& Mdn. & 625 & 969 & 1,643 \\
Deprivation 2 & Mean & 338 & 663 & 1,155 \\
& Mdn. & 298 & 628 & 1,196 \\
Combined & Mean & 530 & 886 & 1,520 \\
& Mdn. & 479 & 776 & 1,296 \\
\hline
\end{tabular}

significantly less activity in Deprivation 2 than in Deprivation 1 (ps $<.001)$. The consistency and generality of the effects of deprivation are further illustrated by the monotonic increases in activity exhibited over the successive periods of deprivation by all Ss with the exception of a single $S$ who showed no further increase in activity from Day 2 to Day 3 during Deprivation 1. Thus, the present results strongly support the widelyheld assumption that deprivation-induced drive states exert a directly energizing effect upon behavior.

\section{References}

Adlerstein, A., \& Fehrer, E. The effect of food deprivation on exploratory behavior in a complex maze. J. comp. physiol. Psychol., 1955, 48, 250-253.

Chapman, R. M., \& Levy, N. Hunger drive and reinforcing effect of novel stimuli. J. comp. physiol. Psychol., 1957, 50, 233-238.

Finger, F. W. Effect of food deprivation on running-wheel activity in naive rats. Psychol. Rep., 1965, 16, 753-757.

Finger, F. W., Reid, L. S., \& Weasner, M. H. Activity changes as a function of reinforcement under low drive. J. comp. physiol. Psychol., 1960, 53, 385-387.

Montgomery, K. C. The effect of the hunger and thirst drives upon exploratory behavior. J. comp. physiol. Psychol., 1953, 46, 315319 .

Richter, C. P. Animal behavior and internal drives. Quart. Rev. Biol., 1927, 2, 307-343.

Zimbardo, P. G., \& Miller, N. E. Facilitation of exploration by hunger in rats. J. comp. physiol. Psychol., 1958, 51, 43-46. 